\title{
A Comparative Retrospective Study of COVID-19 Responses in Four Countries
}

\section{Xiaohan Wang}

Southern Medical University

\section{Leiyu Shi}

Johns Hopkins University

\section{Yuyao Zhang}

Southern Medical University

\section{Haiqian Chen}

Southern Medical University

Jun Jiao

Southern Medical University

\section{Manfei Yang}

Southern Medical University

\section{Gang Sun ( $\sim$ gsun15@jhu.edu )}

Johns Hopkins University Bloomberg School of Public Health https://orcid.org/0000-0002-9642-2886

\section{Research}

Keywords: COVID-19, pandemic, non-pharmaceutical interventions, Healthcare system

Posted Date: August 3rd, 2021

DOI: https://doi.org/10.21203/rs.3.rs-615065/v2

License: (c) (i) This work is licensed under a Creative Commons Attribution 4.0 International License.

Read Full License 


\section{Abstract}

Objective This study compared the government policies and non-pharmaceutical interventions adopted by South Korea, Japan, India, and China in response to COVID-19 during 2020-2021. We hope that our study would propose policies for future COVID-19 waves and provide lessons for future responses to similar infectious diseases.

Methods We made a retrospective study by analyzing the government policies and non-pharmaceutical interventions in these four countries. We utilized policy information and non-pharmaceutical intervention measures from governmental web pages, WHO publications, scientific articles, and conventional media. We summarized the measures implemented in each of these four Asian countries, and assessed the effectiveness of the prevention and control measures.

Results From January 2020 to May 18, 2021, South Korea and Japan experienced three waves of COVID19 epidemic, but the number of daily new confirmed cases per million people was relatively small in both countries, and South Korea had fewer daily new confirmed cases per million than Japan. Following the COVID-19 outbreak in Wuhan in late 2019, China successfully contained the first wave of the outbreak and is not currently experiencing a large-scale resurgence of the epidemic. India is experiencing a grim second wave of the epidemic, with far more daily new confirmed cases per million people than South Korea and Japan. Throughout 2020, the number of COVID-19 deaths per million population remains low in South Korea, Japan, and China, while India has seen an upward trend in deaths per million population since July. As of May 18, 2021, the number of total tests per thousand people in South Korea, India, and Japan was $230.65,181.23$, and 99.59 , respectively. South Korea and India both have more than twice as total tests per thousand people as Japan.

Conclusion Successful practices in China and South Korea show that-case identification and management, coupled with close contact tracing and isolation, is a powerful strategy. The lessons of Japan and India show that social distancing is an effective measure, but only if it is rigor and persistent. Finally, in both developed and developing countries, the development of health care systems and coordinated government leadership play a key role in overcoming epidemics.

\section{Introduction}

Labeled as a black swan event, the coronavirus disease 2019 (COVID-19) pandemic caused by severe acute respiratory syndrome coronavirus 2 (SARS-Cov-2) has emerged in Wuhan, China in December 2019. As COVID-19 continues to diffuse and affect the lives of people around the world, on January 31, 2020, the World Health Organization (WHO) declared COVID-19 a Public Health Emergency of International Concern. ${ }^{[1]}$ The ongoing COVID-19 has already affected over 160 million people, claiming more than 3 million lives in over 200 nations all over the world as of May 18, 2021. ${ }^{[2]}$ In response to "flatten the curve", various nations have tried different approaches to COVID-19 such as social distance, travel 
restrictions, lockdown city, and quarantine. While some countries are still struggling with the COVID-19 pandemic, others are progressing well and rapidly returning to relative normalcy.

The first case of COVID-19 death was reported in China on January 10, 2020. Japan, a neighboring country of China, reported the first case of COVID-19 on January 15. After that, South Korea followed suit on January 20 and India reported on January $30 .{ }^{[3,4]}$ Although Asian countries were hit by the epidemic earlier, the epidemiological impact of COVID-19 has been relatively moderate in most countries except India.

Four representative Asian countries have been selected for analysis, given their relatively similar cultures and nationalities. We selected two developed countries, Japan and South Korea, and two developing countries, China and India, for comparison. This study compared the government policies and nonpharmaceutical intervention measures taken by these four countries to respond to the highly infectious virus during 2020-2021. Countries with varying national economic income can be used as a means of demonstrating this theme in the COVID-19 outbreak response. A study published in Science by the Harvard School of Public Health suggests that the vaccine we have high hopes for will likely do very little. Because the antibodies produced by infected humans may only be effective for 40 weeks ( $<300$ days), shorter than even the development cycle of a vaccine. ${ }^{[5]}$ The future is uncertain, and the practice and lessons learned by governments in combating COVID-19 remain invaluable. We hope that our study would propose policies for future COVID-19 waves and provide lessons for future responses to similar infectious disease outbreaks.

\section{Methods}

We made a retrospective case study by analyzing the government policies and non-pharmaceutical intervention measures of four representative Asian countries (Japan, South Korea, China, and India) in COVID-19 during 2020-2021. We utilized policy information and non-pharmaceutical intervention measures from governmental web pages such as the Korea Centers for Disease Control and Prevention (KCDC), the National Health Commission (NHC) of the People's Republic of China, governmental reports, WHO publications, scientific articles, and conventional media. We summarized the measures implemented in each of these four Asian countries, and assessed the effectiveness of the prevention and control measures.

COVID-19 confirmed cases and deaths were obtained from Johns Hopkins University (JHU), accessed through the Our World in Data database. ${ }^{[6]}$ Total tests per thousand people and the positive rate were also accessed through the Our World in Data database. The case fatality rate is the number of confirmed deaths divided by the number of confirmed cases. Based on epidemiological data we were able to draw various figures by Microsoft Excel. As this case study focuses on the COVID-19 pandemic during 20202021, all the epidemiological data presented are dated between January 2020 and May 2021

\section{Results}




\subsection{Presentation}

\section{General Description in South Korea, Japan, India, and China}

Located across the sea from the Chinese city of Qingdao, South Korea is an East Asian country of 51.6 million inhabitants, with half of the population concentrated in the capital city of Seoul and its metropolitan area. The country has $15.5 \%$ of people over the age of 65 . According to the Organization for Economic Cooperation and Development (OECD), South Korea is a wealthy and developed country with a per capita GDP of 42700 US\$. ${ }^{[7]}$ South Korea's healthcare system is considered one of the best in the world, with a Computed Tomography (CT) Scanners count of 39 per 1 million inhabitants and 12.4 hospital beds per 1,000 inhabitants in 2018. ${ }^{[8]}$

Japan, China's neighbor, is a developed country with 127 million inhabitants residing in $364555 \mathrm{~km}^{2}$, most of the residents live in urban areas (91.8\%). ${ }^{[9]}$ According to the OECD, Japan's GDP in 2019 was per

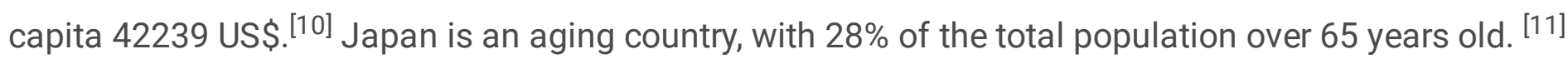
Japan's healthcare system undoubtedly ranks among the best in the world. Japan's total health expenditure in 2019 was 4823 US\$, which was $11.1 \%$ of GDP. General government expenditure on health is $20.28 \%$ of total government expenditure in $2014 .{ }^{[12,13]}$

China and India are both developing countries and the most populous countries in the world. However, India's population density is almost three times that of China, and urban slums may have a population density of more than 250 000/ $\mathrm{km}^{2}$. ${ }^{[14]}$ India's GDP in 2016 was per capita 5901 US\$, and China's GDP in 2017 was per capita 14306 US\$. According to the OECD, India's health system is relatively weak, with only 0.5 hospital beds per 1,000 inhabitants in 2017. General government expenditure on health accounted for only $5.05 \%$ of total government expenditure in 2014. ${ }^{[15]}$ After the lessons learned from SARS in 2003, China has been enhancing its healthcare system. Given the size of the population, China's per capita health resources are also inadequate. Health expenditure per capita in China in 2017 was only 440.83 US\$. ${ }^{[16]}$ General government expenditure on health accounted for $10.43 \%$ of total government expenditure in 2014. ${ }^{[13]}$

\section{Epidemiological Situation of the four Country Regarding COVID-19}

Figure 1 shows the comparison of the daily new confirmed COVID-19 cases per million people in India, Japan, South Korea, and China as of May 18, 2021. The figure was produced and published by Our World in Data. From January 2020 to May 18, 2021, South Korea and Japan experienced three waves of COVID19 epidemic, but the number of daily new confirmed cases per million people was relatively small in both countries, and South Korea had fewer daily new confirmed cases per million than Japan. Following the COVID-19 outbreak in Wuhan in late 2019, China successfully contained the first wave of the outbreak and is not currently experiencing a large-scale resurgence of the epidemic. India is experiencing a grim second wave of the epidemic and has far more daily new confirmed cases per million than South Korea and Japan. 
Figure 2 shows the timeline comparing the cumulative confirmed deaths per million people of COVID-19 in India, Japan, China, and South Korea. Throughout 2020, the number of COVID-19 deaths per million population remains low in South Korea, Japan, and China, while India has seen an upward trend in deaths per million population since July. Japan's number of deaths per million population increases gradually into 2021, and is higher than that of Korea and Japan, while India's number of deaths per million population continues to increase, far exceeding that of Japan, Korea, and China.

Testing is our window into the pandemic and how it spreads, and the positive rate shows the level of detection relative to the size of the outbreak. Figure 3 shows the comparison of the total tests per thousand people and the positive rate for COVID-19 in India, Japan, and South Korea. (Relevant data for China are not fully disclosed) As of May 18, 2021, the number of total tests per thousand people in South Korea, India, and Japan was 230.65, 181.23, and 99.59, respectively. South Korea and India both have more than twice as total tests per thousand people as Japan.

According to the standards published by the WHO in May 2020, a positive rate of COVID-19 less than 5\% indicates that the epidemic situation in a country is under control. We can see that the positive rate of COVID-19 in South Korea is $2.2 \%$, which is lower than the standard announced by the WHO, indicating that the epidemic in South Korea is well controlled. The positive rate in Japan is $6.9 \%$, which is slightly higher than the standard positive rate, while the positive rate in India is $17 \%$, which is much higher than the standard positive rate. The task of epidemic prevention and control is still arduous in India.

\subsection{Management and Outcome}

"Non-pharmaceutical interventions (NPIs)" are social interventions, including isolation, management of sources of infection, social distancing, and so on, aimed at

reducing contact rates in the population and thus reducing the spread of the virus. ${ }^{[17]}$

The major measures taken by South Korea and Japan in response to COVID-19 were summarized in Table 1 from the government infectious disease risk alert approach, immigration, screening, surveillance, healthcare, and society. Table 2 shows the major measures taken by India and China in response to COVID-19.

\section{Government policies and non-pharmaceutical interventions in response to COVID-19 in South Korea and Japan}

The first wave of COVID-19 in South Korea was a cluster of outbreaks linked to a religious group in the city of Daegu and northern Gyeongsang province. The first wave peaked at 813 new cases on February 29,2020 , after which the number of new cases began to gradually decrease. ${ }^{[18]}$ This was followed by a sustained outbreak in small clusters and an increasing number of imported cases from outside Korea. A retrospective look at the fight against the COVID-19 from 2020 to late May 2021 shows that South Korea did not resort to blockades and suspension of public transport to restrict people's movement, even at the 
height of the outbreak. The core of Korea's response to COVID-19 is massive and rapid testing to identify positive cases, along with meticulous tracing and quarantine of all contacts. To provide safe and effective screening for COVID-19, the Drive-Through and Walk-Through Screening Centre have been implemented in Korea. In addition, effective mitigation strategies such as mask-wearing campaigns, social distancing, avoiding crowds, and frequent hand and face washing were implemented.

To avoid the overwhelming of medical resources, Korea prepared for other types of care centers beyond hospital beds. KCDC converted public facilities and residential facilities provided by the volunteer into isolation-and-care facilities and named Life Treatment Centers (LTCs). ${ }^{[19]}$ LTCs can prevent asymptomatic or mildly ill patients from infecting family members. The latest digital technology is also key to the control of COVID-19 in Korea. The Korean government developed Self-Diagnosis Mobile Application to monitor the health of inbound passengers and patients in LTCs. The Korean government has temporarily allowed doctors to engage in telemedicine activities, which can avoid hospital infections and cross-contamination during patient visits. ${ }^{[20]}$

Japan was the third country to have the first COVID-19 case in January 2020 after Thailand. From January 2020 to May 2021, three waves of COVID-19 outbreaks surfaced in Japan. COVID-19 is a disease that mainly threatens the elderly, and Japan has more elderly people per capita than any other country. The first wave of outbreak control focused on avoiding medical resource shortages and reducing deaths due to COVID-19. The Japanese government adopted a strategy of hospitalizing serious patients and isolating the mildly at home. ${ }^{[21]}$ The main measures of the Japanese government were to close schools at the end of February 2020 and to urge the public to wear masks, telecommute, work shifts, not hold events, and avoid contact with others to reduce transmission. ${ }^{[22]}$ Instead of massive testing, the Japanese Government declared a state of emergency on April 17, 2020. ${ }^{[23]}$ Many restaurants and companies reduced the time people spent outside their homes by reducing business hours and shifting to teleworking.

Japan initially adopted a strategy that focused primarily on symptomatic patients, controlling clusters, and seeking ways to coexist with the virus rather than eradicating it. However, after the first wave of the outbreak, socio-economic activities quickly resumed and the epidemic resurfaced. Although the peak period of the second wave of infections was larger than that of the first wave, the number of infections declined in the absence of measures such as a state of emergency. However, during the second wave of the outbreak, Tokyo increased the number of testing. Since early November 2020, the number of infections has started to increase again, and Japan has entered the third wave of the outbreak. The government did not declare a state of emergency, and local governments only called for reduced business hours and limited activities in December 2020. ${ }^{[24]}$ The third wave of the outbreak in Japan is ongoing.

\section{Government policies and non-pharmaceutical interventions in response to COVID-19 in India and China}

India reported the first case of COVID-19 on 30 January 2020. The international community is concerned about India's control strategy and capacity due to high population density, socioeconomic inequalities, 
and low health care resources. India's robust response began at the outset of the pandemic. Border controls such as fever screening, travel history, identification of disease symptoms, and airport screening began in late January 2020. A national lockdown that began on March 24 impacted 1.3 billion individuals. Public health measures such as social distance, hand hygiene, mask use, and telecommuting were also widely practiced. India made every effort to increase health resources, converted train cars into isolation beds. The Government also introduced a mobile phone application named Aarogya Setu for contact tracing and aiding in quarantine. Testing numbers have also increased rapidly, with 553 government labs and 231 private labs nationwide having expanded. ${ }^{[25]}$

Despite a robust response at the outset of the pandemic, India has the world's fastest-growing in absolute numbers as of May 2021. WHO has stated that the "future of the pandemic will depend on how India handles it." ${ }^{[26]}$ From June 2020, India has already gradually relaxed the lockdown measures. With the gradual socio-economic recovery and continued relaxation of restrictions, a second wave of the outbreak emerged in India in February 2021 and gained momentum.

As the country that first identified the COVID-19 outbreak, China took the lead in initiating an unprecedented lockdown. From January 23 to April 8, 2020, Wuhan, the source of the outbreak, suspended all traffic in and out of the city. The central thrust of China's efforts to control the first wave of the outbreak was to actively identify and manage cases, track, and isolate close contacts, and severely restrict or control population movements when feasible and appropriate. ${ }^{[27]}$ The main response policies of the Chinese government include the following levels. Mobility restrictions: Except for the lockdown of Wuhan, schools were closed nationwide, online offices, and non-essential business premises were shut down to minimize the movement of people. Medical resources: The chain of command of the CPC Central Committee and State Council coordinating the joint multi-departmental response allowed the necessary resources to be mobilized. After the outbreak, the Chinese government mobilized medical resources from across the country to support relief efforts in Wuhan and other parts of Hubei, setting up two critical care hospitals and 16 Fangcang hospitals. Case treatment: The policy of ensuring that all those in need are tested, isolated, hospitalized, or treated was implemented. Putting four categories of people - confirmed cases, suspected cases, febrile patients who might be carriers, and close contacts under classified management in designated facilities from Fed 2,2020. Contact tracing: Testing and tracing are a vital part. China adopted the principle of due diligence. Almost the entire city of Wuhan, where the epidemic occurred, has completed nucleic acid testing and screening. It is also the decisive actions and strict measures that have allowed China to control the first wave of epidemics so far, except for sporadic epidemics and imported cases.

\section{Discussion}

COVID-19 is a novel, highly destructive virus with a high basic reproductive number (R0), and can be transmitted during the asymptomatic phase of infection. A Nature survey shows many scientists think that the coronavirus will become endemic- meaning that it will continue to circulate in pockets of the global population for years to come. Control of COVID-19, while difficult, does have some countries with 
successful experiences. Global vaccination is ongoing, but it remains to be seen how effective the vaccine will be in reducing the severity of infection. Reducing transmission through non-pharmaceutical measures will remain critical in the next year or two. In the analysis of COVID-19 response strategies in four representative Asian countries during 2020-2021, we have summarized some effective strategies and identified some shortcomings.

\subsection{Aggressive case identification and quarantine}

Case identification and management, coupled with close contact tracing and isolation, is a powerful strategy. Both China and South Korea, which have achieved better results in COVID-19 control, attach great importance to case identification and quarantine. A model evaluating the effectiveness of NPIs in China showed that without these interventions, COVID-19 cases may increase 67-fold and that early detection and isolation of cases was the most effective measure. ${ }^{[28]}$ Korea's rapid containment of transmission in the first wave of the epidemic, along with the implementation of less stringent social distancing measures, led to widespread international attention to their "test, track, isolate" strategy. However, other countries should note in replicating the measure that the first wave in South Korea was a small cluster of outbreaks. China also locked down the source of the outbreak at the outset, mobilized national health resources to focus on large-scale testing and screening, detected and treated all cases, and isolated close contacts. Aggressive case identification and quarantine measures may be more appropriate to suppress outbreaks promptly at the initial outbreak or when small clusters occur. This may be difficult when the epidemic is larger and spread to a wider area. ${ }^{[29]}$

\subsection{Social Distance}

By appealing or forcing residents to maintain social distance is a potent measure chosen by most countries in the world. However, the enforcement of social distance in countries is decreasing as the outbreak prolongs. Japan's response to COVID-19 was unique in that the authorities did not impose the same rigorous lockdown measures as China and India, nor did they carry out massive testing and screening as in South Korea. Figure 3 shows that Japan's total tests per thousand people are lower than South Korea and India. The state of emergency declared by the Prime Minister and the avoidance of the " $3 \mathrm{C}$ Plus" relied more on the voluntary behaviors of the residents. Instead of quarantining all confirmed patients, the main focus was on treating serious cases and recommending home quarantine for patients with mild symptoms. A study of voluntary behavioral changes during the early stages of the COVID-19 outbreak in Japan showed that a significant portion of the Japanese population voluntarily changed their behavior. ${ }^{[30]}$ Although the first wave was controlled mainly by residents' good hygiene habits and compliance with social distance measures, after Japan launched the "Go To" campaign to revitalize the economy in July 2020, with the increase in population mobility, the second and third wave of epidemics also followed.

India's early response to COVID-19 was very strict, and a widespread lockdown of the country was initiated as soon as possible, but India's lockdown was seriously flawed. India's 140 million people are 
daily-paid migrant laborers; with the imposition of a national lockdown, they are forced to flock back to their villages, unable to comply with the government's advice to maintain social distance. ${ }^{[31]}$ The returning migrant laborer have brought the infection to the rural and peri-urban areas of the country, where public health systems are relatively weak. This has laid the potential for the second wave of the current pandemic in India. In addition, there was a relaxation of social control in India in March 2021, with various traditional cultural festivals being held on several occasions and a complete abandonment of social distance. Maintaining social distance is indeed an important measure, but it can only be effective if it is strictly adhered to over a long period.

\subsection{Healthcare System}

The medical systems in developed and developing countries are facing the ultimate test. The severity of COVID-19 may be affected by the preparedness of the healthcare system. On the one hand, case tracking, testing, and classification management require a well-established community health service system, laboratories, and a large number of health workers; on the other hand, patient treatment and care require medical resources such as doctors, beds, and ventilators. In addition, Personal Protection Equipment (PPE), testing kits, and supportive equipment are also important concerns. South Korea and Japan, as developed countries with well-established health care systems and abundant health resources, do have some significant advantages in controlling outbreaks. But the surge in COVID-19 cases still made it challenging to maintain basic health services.

China has addressed the problem of health resource availability in this COVID-19 outbreak through rapid action and a unique nationwide joint prevention and control system. India has a weak public sector in the health care system, with a large, unregulated private sector. Due to the varying public health services across Indian states, the response and effectiveness of the outbreak varied considerably. Although the healthcare infrastructure has been urgently strengthened and the export of PPE such as masks and protective clothing was banned by the Indian authorities in February 2020, the shortage of doctors will not be remedied overnight. Healthcare personnel was also stigmatized by the general public for having contracted COVID-19 due to inadequate protection. Only the requisitioning of private facilities to support patient care in this situation will increase India's ability to respond to emergencies. ${ }^{[32]}$

\subsection{Government leadership}

A pandemic is a war-like crisis. The powerful government plays a key role in the war. As we can see from the results of the current outbreak response in the four representative Asian countries selected for this study, a strong government does play an important role in outbreak control. The Korean government adhered to the "one team" principle after the outbreak began; it delegated the control and management of infectious diseases to the head of the KCDC by deploying national manpower and medical resources, which allowed for the consistent and systematic command and control throughout the country. China quickly launched a joint prevention and control mechanism to respond to COVID-19; the NHC took the 
lead in setting up a leading group to analyze and judge the situation of the epidemic and provide unified guidance to local governments in handling the outbreak.

The Japanese government failed to adequately reflect on the lessons of the first wave of the outbreak and instead clung to the notion of exceptionalism. Instead of investing in public health, logistics, addressing social and health inequalities, and improving communication with the public, the government prioritized rescuing the restaurant and tourism industries to revive the economy, all of which led to prevention fatigue and reduced public adherence, accelerating the second and third waves of the epidemic. ${ }^{[33]}$

And back in September 2020, a Lancet editorial noted that the Indian government was creating a climate of fatalism and false optimism, with excessive optimism hindering vital public health initiatives. The message to countries is that policymakers should respect scientific evidence and follow the advice of epidemiologists rather than blind confidence and false optimism. As early as September 2020, a Lancet editorial noted that the Indian government was creating a climate of fatalism and false optimism and that excessive optimism hindered vital public health initiatives. ${ }^{\left[{ }^{34]}\right.}$ The enlightenment for all countries is that policymakers should respect scientific evidence and follow the advice of epidemiologists instead of blindly self-confident and falsely optimistic.

\section{Conclusion}

COVID-19 is a new, extremely complex, and highly destructive virus. Although global vaccination is underway, we should not take it lightly. Successful practices in China and South Korea show that case identification and management, coupled with close contact tracing and isolation, is a powerful strategy. The lessons of Japan and India show that social distancing is an effective measure, but only if it is rigor and persistent. Finally, in both developed and developing countries, the development of health care systems and coordinated government leadership play a key role in overcoming epidemics.

\section{Abbreviations}

The coronavirus disease 2019 (COVID-19);

The World Health Organization (WHO);

Severe acute respiratory syndrome coronavirus 2 (SARS-Cov-2)

Johns Hopkins University (JHU)

Korea Centers for Disease Control and Prevention (KCDC)

The National Health Commission (NHC)

Computed Tomography (CT) 
Non-pharmaceutical interventions (NPIs)

Personal Protection Equipment (PPE)

\section{Declarations}

Ethics approval and consent to participate: Not applicable

Consent for publication: Not applicable

Availability of data and materials: All data generated or analyzed during this study are included in this published article.

Competing interests: The authors have no conflicts of interest to declare.

Funding: The National Social Science Fund of China (No. 16BGL184).

Authors' contributions: Xiaohan Wang and Gang Sun conceived the paper. Xiaohan Wang, Jun Jiao and Manfei Yang collected the data. Xiaohan Wang drafted the manuscript. Leiyu Shi, Yuyao Zhang and Haiqian Chen revised the manuscript. Gang Sun contributed to the critical revision of the manuscript for important intellectual content and approved the final version of the manuscript. All authors have read and approved the final manuscript. Xiaohan Wang and Gang Sun are the study guarantors.

Acknowledgements: The authors thank all study participants who have been involved and contributed to the data collection.

\section{References}

1. World Health Organization. Coronavirus Disease (COVID-19) Weekly Epidemiological Update and Weekly Operational Update.

2. https:// Accessed on 25 May 2021.

3. Overview Weekly epidemiological update on COVID-19-18 May 2021.

4. https:// Accessed on 25 May 2021.

5. Korea Ministry of Health and Welfare. The Confirmation of the First Coronavirus Case Who Visited from Abroad. http://ncov.mohw.go.kr/tcmBoardView.do?brdld=\&brdGubun=\&dataGubun=.

6. Pal R, Yadav U. COVID-19 Pandemic in India: Present Scenario and a Steep Climb Ahead. Journal of primary care community health. 2020;11:2150132720939402. https://doi.org/10.1177/2150132720939402.

7. Kissler SM, Tedijanto C, Goldstein E, Grad YH, Lipsitch M. (2020). Projecting the transmission dynamics of SARS-CoV-2 through the post pandemic period. Science (New York, N.Y.), 368(6493), pp. 860-8. 
8. Hannah Ritchie E, Ortiz-Ospina D, Beltekian E, Mathieu J, Hasell B, Macdonald C, Giattino. Cameron Appel, Lucas Rodés-Guirao and Max Roser (2020) - "Coronavirus Pandemic (COVID-19)". Published online at OurWorldInData.org. Retrieved from: 'https://ourworldindata.org/coronavirus' [Online Resource].

9. OECD. (2021), Gross domestic product (GDP) (indicator).doi: 10.1787/ dc2f7 aec -en Accessed on 27 May 2021.

10. OECD. (2021), Hospital beds (indicator). doi: 10.1787/0191328e-en Accessed on 27 May 2021.

11. OECD. (2021), Population (indicator). https://data.oecd.org/pop/population.htm doi: 10.1787/d434f82b-en. Accessed on 27 May 2021.

12. OECD. (2021), Gross domestic product (GDP) (indicator). https://data.oecd.org/ gdp/gross-domesticproduct-gdp.htm. doi: 10.1787/dc2f7aec-en. Accessed on 28 May 2021.

13. Population ages 65. and above (\% of total population). The World Bank Group.

14. https://data.worldbank.org/indicator/SP.POP.65UP.TO.ZS?view=chart. Accessed on 28 May 2021.

15. OECD. (2021), Health spending (indicator). https://data.oecd.org/ healthres/ health-spending.htm. doi: 10.1787/8643de7e-en. Accessed on 28 May 2021.

16. WHO. (2021), GHO (indicators).

17. https:// Accessed on 28 May 2021.

18. Pal R, Yadav U. COVID-19 Pandemic in India: Present Scenario and a Steep Climb Ahead. Journal of primary care community health. 2020;11:2150132720939402.

19. OECD. (2021), OECD Data. https://data.oecd.org/india.htm. Accessed on 30 May 2021.

20. The World Bank Group. Current health expenditure per capita (current US\$).

21. https://data.worldbank.org/indicator/SH.XPD.CHEX.PC.CD Assessed on 30 May 2021.

22. Eubank S, Eckstrand I, Lewis B, Venkatramanan S, Marathe M, Barrett CL. (2020). Commentary on Ferguson, et al., "Impact of Non-pharmaceutical Interventions (NPIs) to Reduce COVID-19 Mortality and Healthcare Demand". Bulletin of mathematical biology, 82(4), 52.

23. Peck KR. (2020). Early diagnosis and rapid isolation: response to COVID-19 outbreak in Korea. Clinical microbiology and infection: the official publication of the European Society of Clinical Microbiology and Infectious Diseases, 26(7), 805-807. https://doi.org/10.1016/j.cmi.2020.04.025.

24. Park PG, Kim CH, Heo Y, Kim TS, Park CW, Kim. C-H. Out-of-hospital cohort.

25. treatment of coronavirus. disease 2019 patients with mild symptoms in Korea.

26. an experience from a single community treatment center. J Korean Med Sci.

27. 2020:35:e140.

28. The Government of the Republic of Korea. Tackling COVID-19 Health, Quarantine and Economic Measures: Korean Experience. Sejong: Ministry of.

29. Economy and Finance; Mar 31, 2020.

30. Basic guidelines for novel Coronavirus disease response. 2020. https://www. 
31. mhlw.go.jp/content/10900000/000608655.pdf. Assessed 31 May 2021.

32. Ministry of. Health, Labor, and Welfare. Basic policies to combat COVID-19. https://www.mhlw.go.jp/content/10900000/000599698.pdf. Accessed 31 May 2021.

33. Prime Minister's Office of Japan. COVID-19 Control Headquarters (27th meeting).https://www.kantei.go.jp/jp/98_abe/actions/202004/07corona.html/. Accessed 31 May 2021.

34. Karako K, Song P, Chen Y, Tang W, Kokudo N. Overview of the characteristics of and responses to the three waves of COVID-19 in Japan during 2020-2021. Bioscience trends. 2021;15(1):1-8. https://doi.org/10.5582/bst.2021.01019.

35. Indian Council of Medical Research. Total operational (Initiated independent testing) laboratories reporting to ICMR. Published June 8, 2020. Accessed 31 May 2021.https://www.icmr.gov.in/pdf/covid/labs/archive/COVID_Testing_Labs_08062020.pdf.

36. World Health Organization. FIFA/COVID-19 virtual press conference. https://www.who.int/docs/default-source/coronaviruse/transcripts/who-audio-emergenciescoronavirus-press-conference-full-23mar2020.pdf?sfvrsn=846ecb41_4 Accessed 31 May 2021.

37. Li Z, Chen Q, Feng L, et al. Active case finding with case management: the key to tackling the COVID19 pandemic. Lancet. 2020;396(10243):63-70.

38. Lai S, Ruktanonchai NW, Zhou L, et al. Effect of non-pharmaceutical interventions to contain COVID19 in China. Nature. 2020;585(7825):410-3.

39. Karako K, Song P, Chen Y, Tang W, Kokudo N. Overview of the characteristics of and responses to the three waves of COVID-19 in Japan during 2020-2021. Bioscience trends. 2021;15(1):1-8. https://doi.org/10.5582/bst.2021.01019.

40. Dighe A, Cattarino L, Cuomo-Dannenburg G, et al. Response to COVID-19 in South Korea and implications for lifting stringent interventions. BMC Med. 2020;18(1):321. https://doi.org/10.1186/s12916-020-01791-8.

41. The Lancet. India under COVID-19 lockdown. Lancet. 2020;395:1315. doi:10.1016/S01406736(20)30938-7.

42. Second joint statement of the IPHA, IAPSM and IAE- Public health approach for COVID-19 pandemic control in India. (2020). Indian journal of public health 64(Supplement), 84-6. https://doi.org/10.4103/0019-557X.285636.

43. Shimizu K, Tokuda Y, Shibuya K. (2021). Japan should aim to eliminate covid - 19. BMJ (Clinical research ed.), 372, n294. https://doi.org/10.1136/bmj.n294.

44. The Lancet. COVID-19 in India: the dangers of false optimism. Lancet. 2020;396(10255):867.

45. 34. The Lancet (2020). COVID-19 in India: the dangers of false optimism. Lancet (London, England), 396(10255), 867.

\section{Tables}


Table 1 The major responses to COVID-19 in South Korea and Japan 
A. KCDC raised the COVID-19 alert to the highest level to strengthen the overall response system on February 23, 2020.

B. The government has

Government Infectious Disease Risk Alert Approach

\section{Immigration and Screening Measures}

\begin{abstract}
A. In the early stages of the epidemic, the government focused on special entry procedures, mandatory "SelfCheck" Mobile APP and other monitoring measures to track and monitor the health status of inbound travelers upon arrival.
\end{abstract}

B. Mandatory COVID-19 testing and two-week quarantine for inbound travelers.

C. In late June, country-specific restrictions began, suspending visa issuance and unscheduled flights and requiring submission of negative PCR-test results when issuing tickets to South Korea.

D. For travelers with $A 1, A 2$ and $A 3$ visas and essential travelers will be tested for COVID-19 upon arrival. They will be actively monitored for 14 days if the test is negative.
A. Japanese Ministry of Foreign Affairs gradually raised the risk alert for the epidemic level.

B. The Ministry of Health, Labor, and Social Affairs, with the Government's aid, set up a cluster response team along with 536 consultative centers.
A. The government reinforced travel restrictions to and from China, South Korea, and other countries.

B. Returning residents and long-term pass holders with travel history to these affected regions is subject to 14-day quarantine.

C. Japan gradually relaxed immigration restrictions starting on October 1, 2020. 


\section{A. Testing}

Surveillance Measures
1.For safe and efficient COVID19 screening, the Drive-Through Screening Centre has been implemented in Korea. The entire service takes approximately 10 minutes for one tester without leaving his or her car.

\section{Walk-Through Screening} Station was devised in Korea for people who cannot drive.

3.KCDC rapidly scaled up the diagnostic capacity within South Korea. Laboratory test for COVID-19 was initially performed at KCDC and then became available at 17 regional laboratories throughout the nation, on 24 January 2020.

\section{B. Tracing}

The Korean government utilized advanced digital technology to track people who came into close contact with the confirmed cases, and place them under self-quarantine.

\section{A. Testing}

1.The need for PCR testing was downplayed, and extensive testing was rejected by the government's scientific advisers in the early stage.

2. PCR testing start to increase from July 2020.

\section{B. Tracing}

1.The authorities used retrospective monitoring methods to find closer links to an infected person. The basic policy was to early detect the source of an infected individual, follow all the people in the cluster who are highly transmissible, test and isolate them immediately and treat them rather than general testing of the country's entire population.

2. On June 19,2020 , the government released a tracing app named "COCOA".

\section{A. The Korean government introduced the policy of "distancing in daily life" to support the maintenance of normal life starting on March 22, 2020.}

Five key rules govern personal distancing in daily life:

-Stay home for 3-4 days if you feel unwell;

'Keep a distance of 2 arms' length from others;

\section{Public Health Measures}

-Wash your hands for 30 seconds and cough or sneeze into your sleeve;

-Ventilate spaces at least twice a day and disinfect regularly;
A. "3Cs"

In order to raise public awareness, the government encouraged people to avoid 3Cs. The places that meet the 3Cs are closed spaces, crowded places, and close-contact settings. Later Japan updated into "3C Plus" that included behavior modifications like avoiding loud talking and singing.

B. On April 17, 2020, Prime Minister declared a national emergency. Many restaurants and companies reduced the time people spent outside their homes by reducing business hours and shifting to teleworking. The state of emergency was lifted on May 25,2020.

Local governments began enforcing reduced business hours and limited activities in December,2020.

C. Other public health measures: 
Stay connected while physically distancing.

B. Strengthening other public health measures:

cancelling mass gatherings,, $\mathbb{Z}$

mask-wearing campaigns;

frequent hand and face washing.
-Sports and entertainment events were canceled in Japan for two weeks from 26 February through 13 March.

-The decision was made to close schools in late February, 2020.

- Stay-at-home request

-Calling on the public to wear masks, telework, shift work hours, refrain from holding events, avoid large gatherings, avoid unimportant trips, and avoid contact with other people.

\section{A. LTCs}

On March 2, 2020, the Korean government started Life Treatment Centers (LTCs) to provide quarantine, treatment, and monitoring for asymptomatic and mildly symptomatic patients outside of hospitals.

By March 25, a total of 17 LTCs were serving patients with mild symptoms nationwide.

B. The Korean government covers the cost of diagnosis and treatment for confirmed cases (Korean citizens and certain foreign nationals)

C. Provide hospital beds based on the severity of a patient's case to make efficient use of limited medical resources.

\section{A. The country coordinated hotels to prevent}

the hospital rush and asked the non-critical patients to stay at home or the designated hotels. B. The government implemented robots to take care of patients in hotels and hospitals so that people can restrict their interactions with humans.

C. Japan created dedicated wards for patients while securing dedicated accommodations for asymptomatic patients in march.

As of 27 May, 2020, Japan had about 18,000 beds and about 19,000 rooms available nationwide for patients with COVID-19.

D. Early patient diagnosis and enhancement

of intensive care and the securing of a medical service system for the severely ill.

\section{Table 2 The major responses to COVID-19 in India and China}




\section{Government Infectious Disease Risk Alert Approach}

A. On January, 25,2020 , the government issued a travel warning asking the public to avoid non-essential travel to China.

B. A Joint Task Force of eminent public health experts of India was constituted by Indian Public Health Association (IPHA), and Indian Association of Preventive and Social Medicine (IAPSM) in April 2020 to help the Government of India for containment of COVID-19 pandemic in the country. Subsequently, Indian Association of Epidemiologists (IAE) also joined the Task Force.
A. On January 1,2020 , the NHC set up a leading group on the COVID-19 response.

B. China informed the WHO of developments and the initial progress that had been made in determining the cause of the viral pneumonia.

C. On January 20, 2020, the NHC set up a leading group for COVID-19 response to guide the local response and disposal of the outbreak.
Immigration and Screening Measures
A. On February 2, 2020, the electronic visa service for Chinese citizens was discontinued.

B. India suspended almost all existing visas except for essential visas till April 15, 2020. Later extended to May 3, 2020.

C. Health screening of travelers at airports and border ports. All incoming travelers from countries with severe outbreaks shall be quarantined for a minimum period of 14 days.
A. On April 1, 2020, Chinese customs began nucleic acid testing on inbound arrivals at all points of entry - air, water and land.

B. For people with a history of travel or residence in countries or regions with serious epidemics, strengthen port health quarantine and health screening.

\section{A. Testing}

1. On April 13,2020 , the Indian Council of Medical Research (ICMR) issued an announcement recommending that laboratories
A. Four categories of people classification management

1. Wuhan began to adopt measures to put four categories of people confirmed cases, suspected cases, febrile patients who might be carriers, and close contacts - under classified 


\section{Surveillance Measures}

adopt "Pool Testing" for novel coronavirus testing to increase testing capacity and volume while achieving significant savings in testing costs.

2. Initially, the testing for coronavirus was limited to those high-risk patients characterized by a variable combination of symptoms, close contacts, and travel history.

\section{B. Tracing}

The Government introduced a mobile phone application named Aarogya Setu for contact tracing and aiding in quarantine and related containment measures. management in designated facilities from Fed 2,2020.

\section{B. Tracing}

1.The policy of ensuring that all those in need are tested, isolated, hospitalized or treated was implemented. Actions were taken to conduct mass screenings to identify people with infections, hospitalize them, and collect accurate data on case numbers.

2. President $X i$ required that epidemic control measures be improved and strengthened and that the principle of early detection, reporting, quarantine and treatment be strictly observed.

\section{A. Lockdown Measures}

Nationwide lockdown has been imposed since March 25, 2020. All educational institutions, malls, public events, small shops other than those which sold food were closed and public transport and international flights were banned, and on 14 April the lockdown was extended till 3 May.

The Indian government issued

\section{Public}

Health Measures "lifting lockdown" measures in succession between June and September,2020.

Indian states began implementing varying degrees of restrictions in late March, 2021.

\section{B. Other public health measures:}

1.On April 9, New Delhi, Mumbai and other states introduced mandatory regulations for all travelers, who must wear masks.

\section{A. Lockdown Measures}

1. On January 23,2020 , the government put the Wuhan city under lockdown by shutting services at the airport, railway stations, ferry ports and long-distance bus stations. Then the whole of Hubei Province went into lockdown. On April 8, 2020, Wuhan lifted lockdown.

\section{B. Other public health measures:}

1.The authorities extended the Chinese New Year holiday of 2020 and delayed school opening.

2.From January 23 to January 29 , 2020 , all provinces and equivalent administrative units on the Chinese mainland (hereafter all provinces) activated Level 1 public health emergency response. Work places and school closures have begun in various areas, and activities related to the catering, entertainment and tourism industries have been suspended. Citizens wear masks outside and enter public places with temperature screening. 
2.The government recommends that all state governments adopt a "Work from Home Policy" and pay wages as usual.
3. Implementing community closed management nationwide. Residents in and out of the community register and check their body temperature.

\section{Healthcare Measures}

A. Nearly 60,000 isolation beds have been erected at all levels of quarantine agencies and stations in India.

B. Modification of about 20,000 train carriages for isolation of confirmed patients.

C. Launch of the Bangalore International Exhibition Centre's Mobile Cabin Hospital on June 27,2020 , which closed on September 4, 2020.

D.A mobile phone application named Sanjivan was introduced in India for registering for home isolation, checking bed availability and requesting ambulances, as well as a dedicated hotline number for remote consultations.

\section{Medical Assistance Operation}

China launched medical assistance operation, mobilized all its medical resources to support the efforts in Wuhan and other locations in Hubei. From January 24, 2020, Chinese New Year's Eve, to March 8, 2020, it rallied 346 national medical teams, consisting of 42,600 medical workers and more than 900 public health professionals to the immediate aid of Hubei and the city of Wuhan.

\section{Makeshift Hospitals}

China mobilized 40,000 construction workers and several thousand sets of machinery and equipment to build two hospitals. The construction of the 1,000-bed Huoshenshan Hospital was completed in just 10 days, and that of the 1,600-bed Leishenshan Hospital in just 12 days. In 10 short days, 16 Mobile Cabin Hospital providing over 14,000 beds were built. 4. Hospital capacity must be boosted to ensure admission and treatment for all patients

\section{Figures}




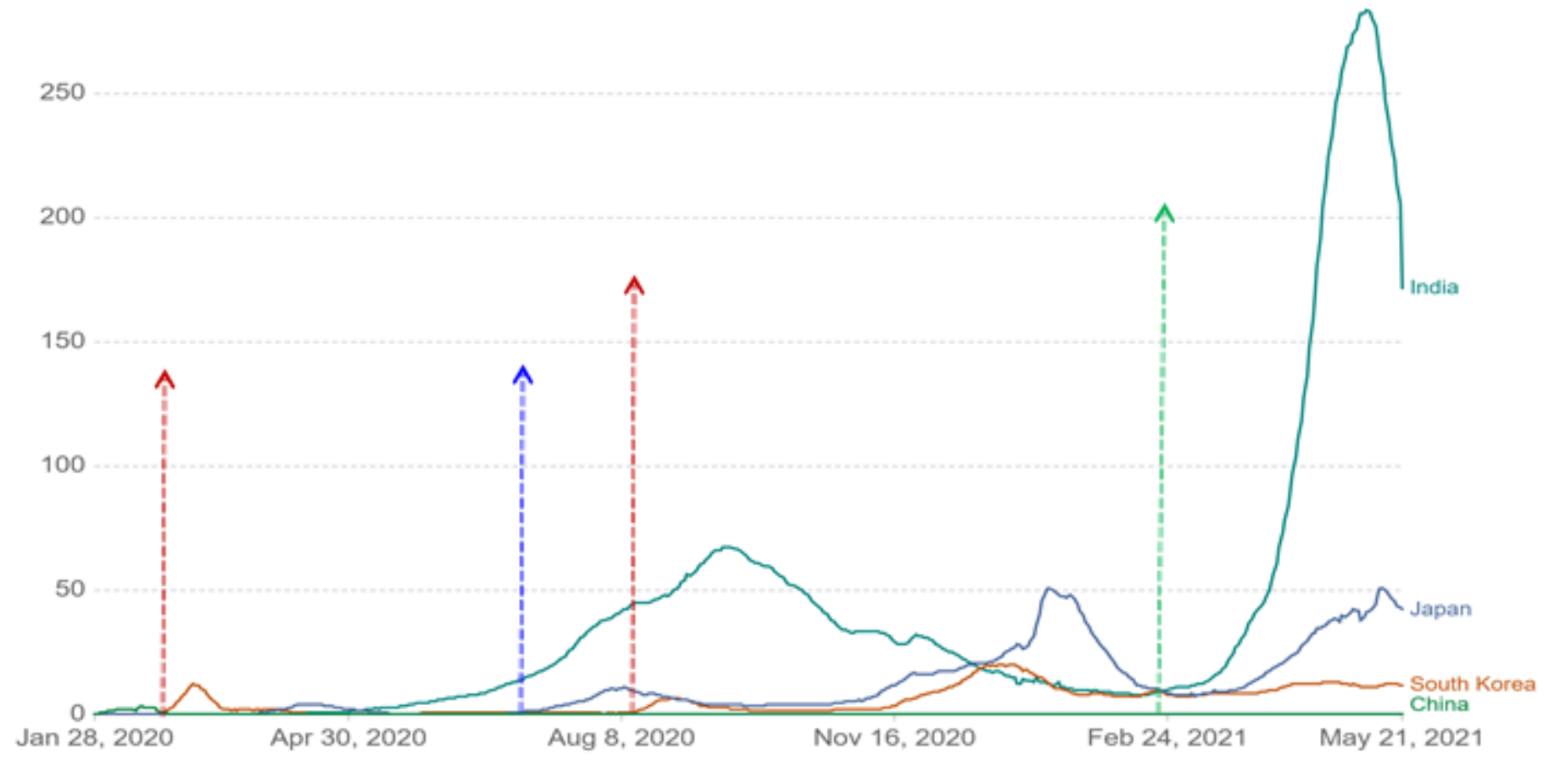

\section{Figure 1}

Comparison of the daily new confirmed COVID-19 cases per million people in India, Japan, South Korea, and China. (Show is the rolling 7-day average; as of May 18, 2021) Note: A1 First wave infections related to Shicheonji; A2: Second wave infections related to Sarang Jeil Church; B1: Government initiated "Go To" campaign; $\mathrm{C} 1$ : The second wave of the epidemic has begun in Maharashtra; 


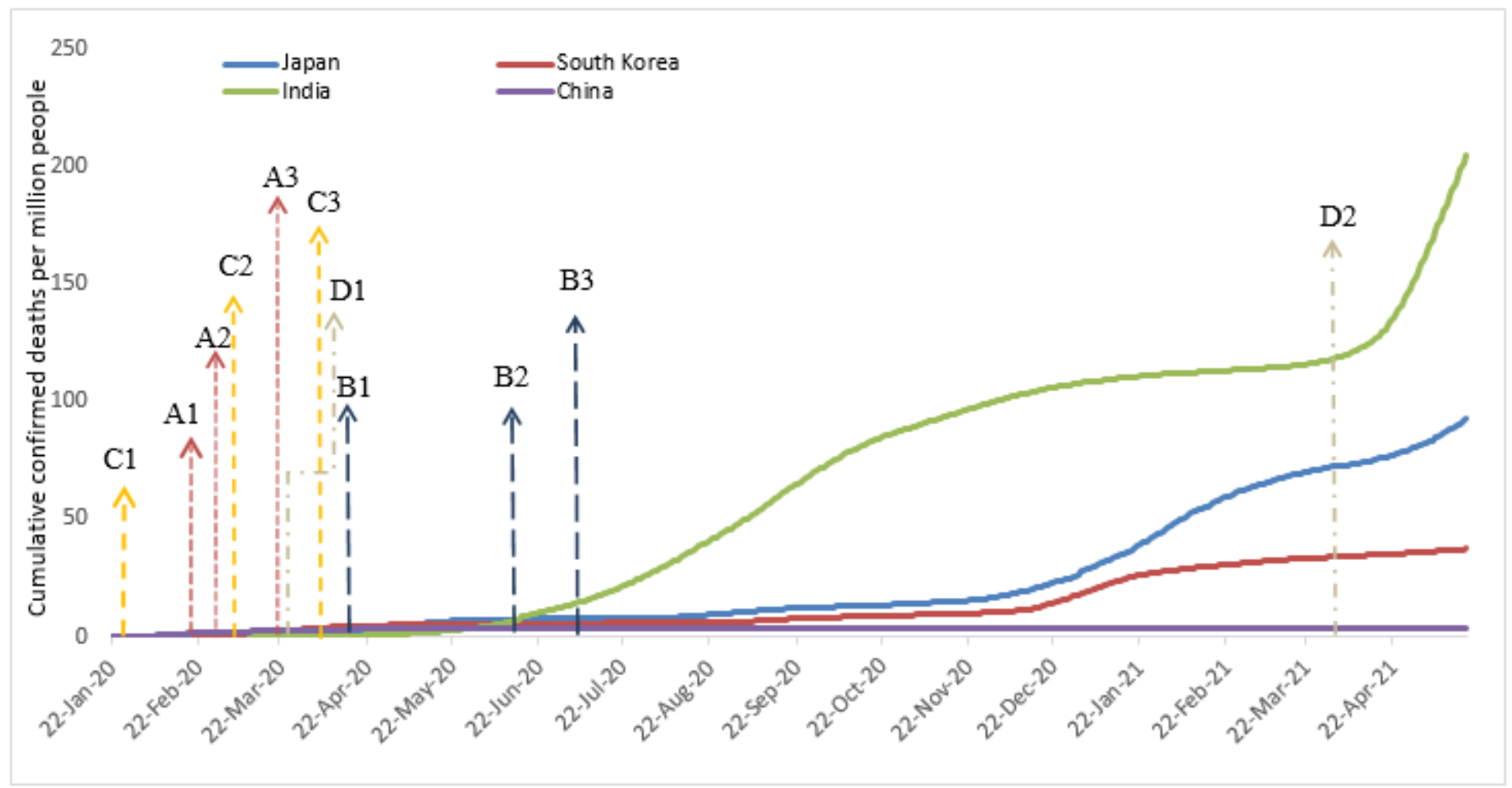

\section{Figure 2}

Timeline comparing the cumulative confirmed deaths per million people of COVID-19 in India, Japan, and South Korea. (as of May 18, 2021) Note: A1: The Korean government carried out mass testing from 19 February 2020. A2: KCDC Launched LTCs on March 2, 2020. A3: The Korean government introduced "distancing in daily life" to support the maintenance of normal life starting on March 22, 2020. B1: On April 17, 2020, the Japanese Prime Minister declared a national emergency. B2: Tracing- on June 19, 2020, the Japanese government released a tracing app named "COCOA". B3: Testing- PCR testing starts to increase from July 2020 in Tokyo. C1: Lockdown Wuhan on January 23, 2020; C2: China launched medical assistance operation to support Wuhan and other locations in Hubei from January 24 to March 8, 2020. C3: From 8 April 2020, Wuhan was lifted from lockdown and entered a phase of ongoing epidemic prevention and control. D1: Nationwide lockdown has been imposed in India since March 25, 2020. D2: Indian states began implementing varying degrees of restrictions in late March 2021. 


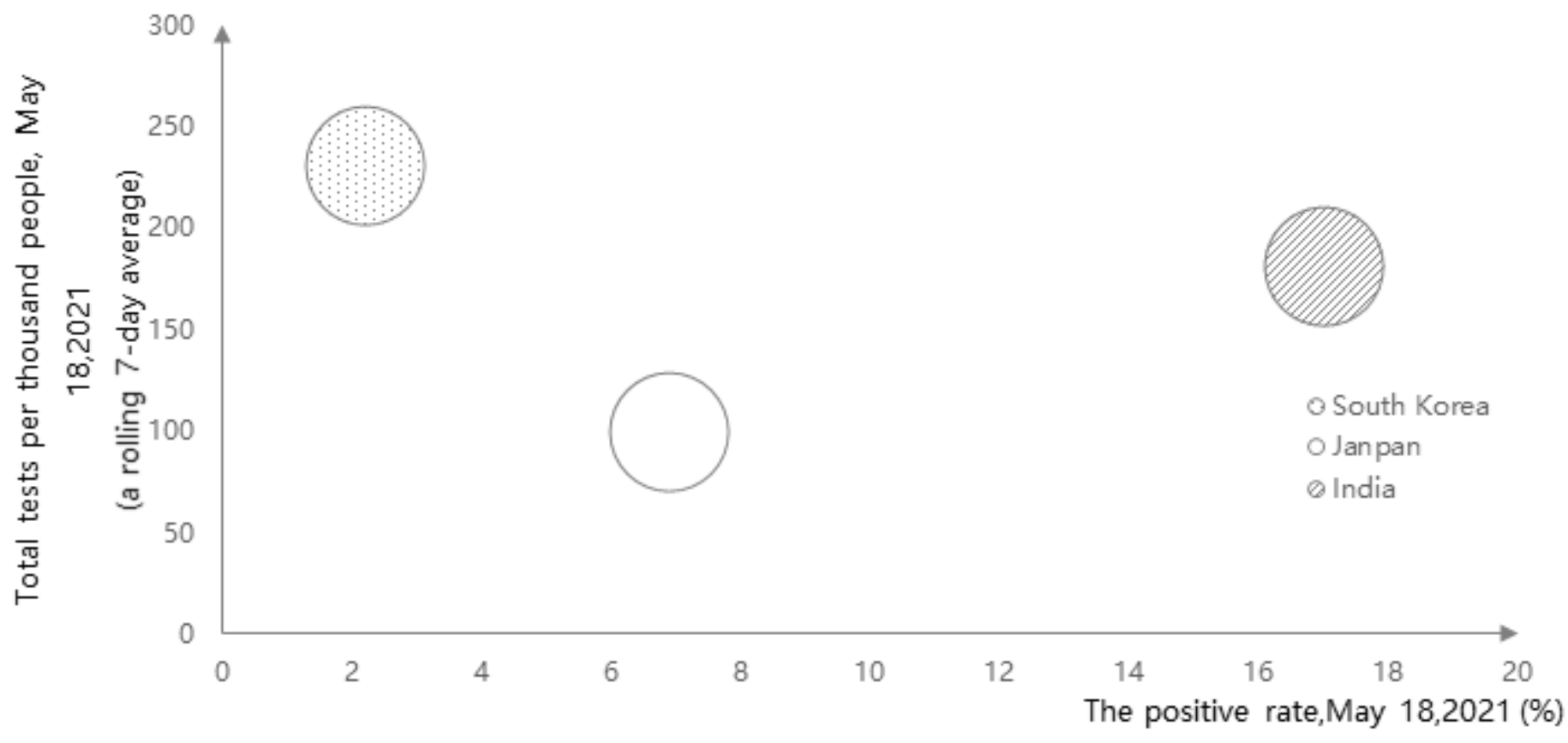

Figure 3

Comparison of the total tests per thousand people and the positive rate for COVID-19 in India, Japan, and South Korea. (May 18, 2021) 